\title{
RESIDUAL LUMINESCENCE IN QUARTZ FROM SLACK WATER DEPOSITS IN KAVERI BASIN, SOUTH INDIA: A SINGLE ALIQUOT APPROACH
}

\author{
MANOJ K. JAISWAL ${ }^{1}$, YUE GAU CHEN ${ }^{1}$, VISHWAS S. KALE ${ }^{2}$ and HEMA ACHYUTHAN ${ }^{3}$ \\ ${ }^{1}$ Department of Geosciences, National Taiwan University, Taipei-10617, Taiwan, \\ ${ }^{2}$ Department of Geography, University of Pune, Pune- 411 007, India \\ ${ }^{3}$ Department of Geology, Anna University, Chennai-600 025, India
}

Received 19 February 2009

Accepted 7 May 2009

\begin{abstract}
Optical bleaching of quartz may be incomplete due to decreased daylight intensity and narrower wavelength spectrum in water column, leading to age overestimation in young fluvial sediments. This hypothesis was tested on a low energy slack water deposits from Kaveri Basin in south India using the SAR protocol. Various tests suggest successful application of SAR on quartz from the study area despite low sensitivity and few numbers of bright grains. Partial bleaching can be ruled out if using SAR on small aliquots. The results suggest a uniform residual luminescence and a common sedimentary condition in this area. Due to partial bleaching, the lowest values of palaeodoses should be considered in preference to the average values.
\end{abstract}

Keywords: Optical dating, OSL dating, slack water deposit, Kaveri flood plain.

\section{INTRODUCTION}

The assumption of daylight bleaching of quartz to reset the optical dating clock in fluvial samples may not hold well due to decreased intensity and narrow range of wavelength spectrum in water column. The usual cause of age overestimation is due to residual luminescence from previous burial history of the sediments (Berger and Luternauer, 1987; Berger, 1990; Ditlefsen, 1992; Spooner, 1993; Olley et al., 1998; Stokes et al., 2001; Fuchs et al., 2005). Single Aliquot Regeneration (SAR) protocol of luminescence dating facilitates the identification of the status of partial or poor bleaching and helps in identifying the most bleached part of the sediments. Successful application of single aliquot/single grain has promoted its application to a variety of fluvial and glacial deposits. However, the problem still persists and may vary from one geographic setting to another, depending on both of the depositional environments and distance of transport.

Flood deposits are an important archive for the study of past climatic conditions and their influence to the human society. For estimating the recurrence interval of

Corresponding author: M. K. Jaiswal

e-mail: mkjosl@gmail.com large floods, one needs to know the time and number of floods equal to a given magnitude or greater than a threshold value. To get the past records of flood deposit (palaeo-floods), we need to date them as historical records are limited to a few decades or 1-2 centuries only. Low energy slack-water flood deposits (SWDs) are finegrained sand and silts that settle out of suspension in protected areas of reduced flow velocity during highmagnitude floods. Deposition occurs in areas like backflooded tributaries, eddy zones or along the irregularities in the channel margin (Baker et al., 1988). A typical SWDs corresponding to one flood event would constitute the bottom sand followed by silt and invariably capped by clay drape (Kale et al, 2000; Kale et al., 2003). The vertical stacking of such units would imply that each flood event was higher than the preceding one. Hydrologists use these records to reconstruct the palaeo-flood history of a river much beyond the historical record.

In the recent years some progress has been made using the luminescence dating technique on dating flood events. Olley et al. (1998) examined 70 year old flood sediment from the Murrumbidgee River and found that ages computed from the mean palaeodose varied from 400 to 1000 years depending on the grain size, with the coarser size being relatively better bleached. He com- 
puted the lower $5 \%$ of the palaeodoses and results were consistent with the known historical records; however, he suggested that least $12 \%$ of the aliquots had apparent doses consistent with zero, indicating that aliquots contained fully bleached grains. Fuchs et al. (2005) studied fine grain and coarse grain quartz and feldspar from the 2002 millennium flood in Saxony and found that residual luminescence varied from 0.5 to $16 \mathrm{~Gy}$; however, fine grain quartz was the best bleached but still having a residual $D_{\mathrm{e}}$ equivalent to an age of $\sim 140-450$ years. Jaiswal (2006) studied the young $(<2 \mathrm{ka})$ slack water deposit at mountain front of NW Himalayas and shown that age based on the mean $D_{e}$ was almost 2 times higher than of least $10 \%$ ages. A significantly high scatter up to $40 \%$ was found on mean ages. The least $10 \%$ on modern sample gave 400 years in age whereas the mean was $\sim 1060$ years. Jaiswal (2006) studied the catastrophic flood in NW Himalayas occurred in 1970 and concluded the residual age of $\sim 400$ years, based on an estimate from minimum $\mathrm{D}_{\mathrm{e}}$ 's. This suggest that age based on the mean $D_{e}$ significantly overestimated the actual age in the case of young ( $<2 \mathrm{ka}$ ) flood sediments. Jain et al. (2004) synthesized optical dating on many fluvial archives of various ages and suggested to consider minimum values of palaeodoses for young fluvial samples $(<2 \mathrm{ka})$ and mean ages for older samples $(>2 \mathrm{ka})$ as the amount of partial bleaching is negligible compared to the age. In summary, previously published work shows that partial bleaching of fluvial sediment still remains a potential problem in luminescence dating, which needs extensive study to clarify.

Therefore, SWDs were chosen to test the residual luminescence and the applicability of SAR in a young slack water deposit in Kaveri Basin, southern India. This study also aims to establish the luminescence chronology of the past floods of few hundred years. Since a longer time is involved in slack water sedimentation, it can be assumed that pre-depositional bleaching of such sediment is adequate but at the same time, suspension load of the river, blocks the daylight and may result in to partial bleaching prior to deposition. Present work is a part of the project on estimating the past-flood magnitude and recurrence interval in Kaveri Basin in south India. The work examines partial bleaching for the studied section using a modern analogue of slack water deposit.

\section{A BRIEF OF GEOLOGY OF THE STUDIED AREA AND SAMPLE LOCATION}

With a catchment area of about $81155 \mathrm{~km}^{2}$ the Kaveri River is a major river of southern India. It originates in the Western Ghat and flows towards east to enter the Bay of Bengal. The middle reach of the river is characterized by the $c a$. $95 \mathrm{~km}$ long Kaveri Gorge developed into charnockitic and granitic rocks of Archean age (Sharma and Rajamani, 2001). The SWD site $\left(12.18^{\circ} \mathrm{N}, 77.73^{\circ} \mathrm{E}\right)$ is located in the lower part of the gorge (Fig. 1), a few $\mathrm{km}$ upstream of the famous Hogenkal Falls. Also it is geomorphologically in a small, back-flooded tributary of the Kaveri River, known as the Bennatti Halla, close to Biligundlu village.

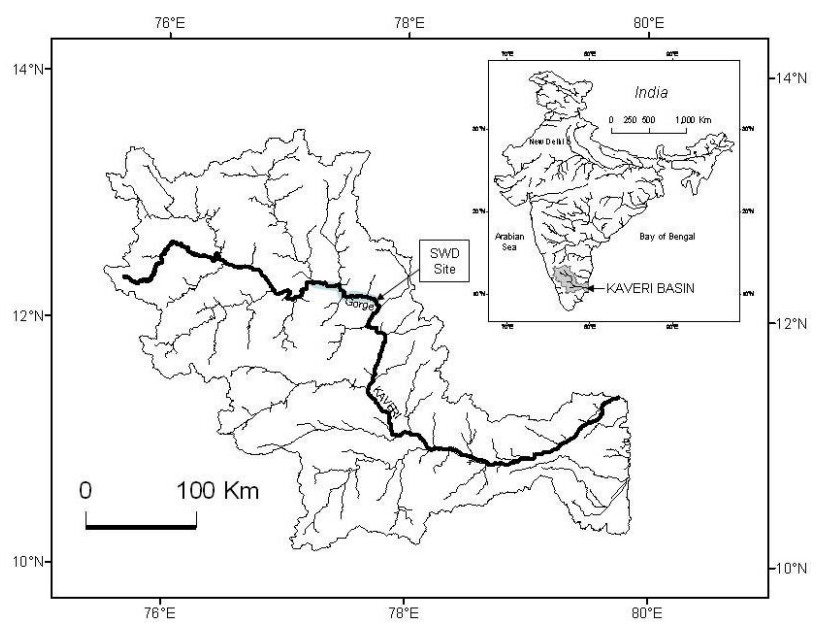

Fig. 1. Map showing the location of the Kaveri Basin in India and the SWD site discussed in the text.

Available gauge data indicate that the highest flood on the Kaveri River in the recent decades was recorded in 1991. This flood $\left(\sim 7000 \mathrm{~m}^{3} / \mathrm{s}\right)$ on Kaveri, back-flooded the Bennatti Halla and over-topped the SWDs. All other floods recorded during the gauge period were at least a meter lower than the 1991 flood stage. Four SWD samples, namely BLU-SWD-1, 2, 3 and 4, were collected from two pits excavated along the Bennatti Halla near the Kaveri River channel. BLU-SWD-1 was collected at $18 \mathrm{~cm}$ from the top and BLU-SWD-2 was taken at $93 \mathrm{~cm}$ from the top from a $118 \mathrm{~cm}$ deep pit located along the Bannatti Hall (Fig. 2). Sample BLU-SWD-1 was considered as the modern analogue of the deposit ( $\sim 18$ years old from historical data), while there was no independent age control for the sample BLU-SWD-2 collected from the bottom. Similarly, samples (BLU-SWD-3 and 4) were collected from the top ( $33 \mathrm{~cm}$ from the top) and bottom (138 $\mathrm{cm}$ from the top) of another $126 \mathrm{~cm}$ deep pit, located on the left bank of the Bennatti Halla at a distance of $\sim 425 \mathrm{~m}$ away from the present channel bank of the

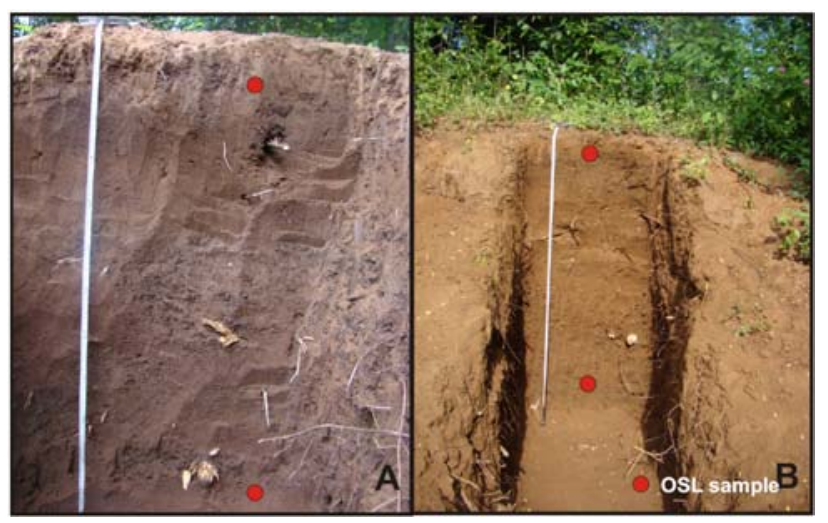

Fig. 2. Field photographs of the slack water deposit of the Kaveri river exposed in pits excavated along the Bennati Halla. (A) Pit-1 located about $100 \mathrm{~m}$ away from the kaveri and Bennati Halla confluence. (B) Pit-2 section situated nearly $425 \mathrm{~m}$ from the confluence. Samples for OSL dating were collected from the upper and lower level units of each pit. As discussed, the samples from upper unit should be less than a century old. 
Kaveri River. The top sample was supposed to be deposited in the last few tens of years. A total of 130 samples were collected from these pits to study the texture for identifying individual flood units.

\section{METHOD AND INSTRUMENTATION}

The quartz fraction from samples was extracted by treating them sequentially with $\mathrm{HCl}, \mathrm{H}_{2} \mathrm{O}_{2}$ and heavy liquid separation using Sodium Polytungstate (density = $\left.2.58 \mathrm{~g} / \mathrm{cm}^{3}\right)$. These grains were then sieved to get $90-150 \mu \mathrm{m}$ size range and etched using $40 \% \mathrm{HF}$ for 80 minutes followed by $12 \mathrm{~N} \mathrm{HCl}$ treatment for 40 minutes. The purity of quartz vis-à-vis feldspar contamination was tested using Infrared Stimulated Luminescence (IRSL). The grains were mounted on stainlesssteel disks using Silko-Spray silicone oil. Very small aliquots ( $\sim 60-100$ grains) were not preferred due to low intensity and very low number of bright grains (discussed later). Thus, a small aliquot containing 300-400 grains were preferred considering that the detection of insufficient bleaching is possible with small aliquots containing
200-500 grains (Fuchs et al., 2003). Luminescence measurements were made on a Riso TL/OSL-12 system with a blue LED source $(470 \pm 30 \mathrm{~nm})$ for stimulation up to 40 seconds. A filter pack of BG-39 and U-340 was used to measure the luminescence in UV region. Beta source ${ }^{90} \mathrm{Sr} /{ }^{90} \mathrm{Y}$ delivering a dose rate of $0.231 \mathrm{~Gy} /$ second was used for irradiation.

A 5 point single aliquot regeneration (SAR) protocol suggested by Murray and Wintle (2000) was applied on all the samples. Three regeneration dose points were used for constructing dose growth curve and two points were to check for recuperation effect and sensitivity corrections (recycled point) respectively (Fig. 3). A preheat of $220^{\circ} \mathrm{C} / 10$ seconds (selected on the analysis based on a preheat plateau, discussed later) for natural and regeneration doses and a cut heat of $160^{\circ} \mathrm{C}$ for test doses was used. The examined quartz shows a typical shine down curve and the palaeodoses were calculated by interpolating the natural $\mathrm{L}_{\mathrm{n}} / \mathrm{T}_{\mathrm{n}}$ on the linearly fitted dose-growth curves (Fig. 3A). Palaeodoses were selected having variation in recycling ratio less that $10 \%(1 \pm 0.1)$. The initial part $(0.8$ second of a 40 seconds exposure with background subtracted) of a typical shine down curve of

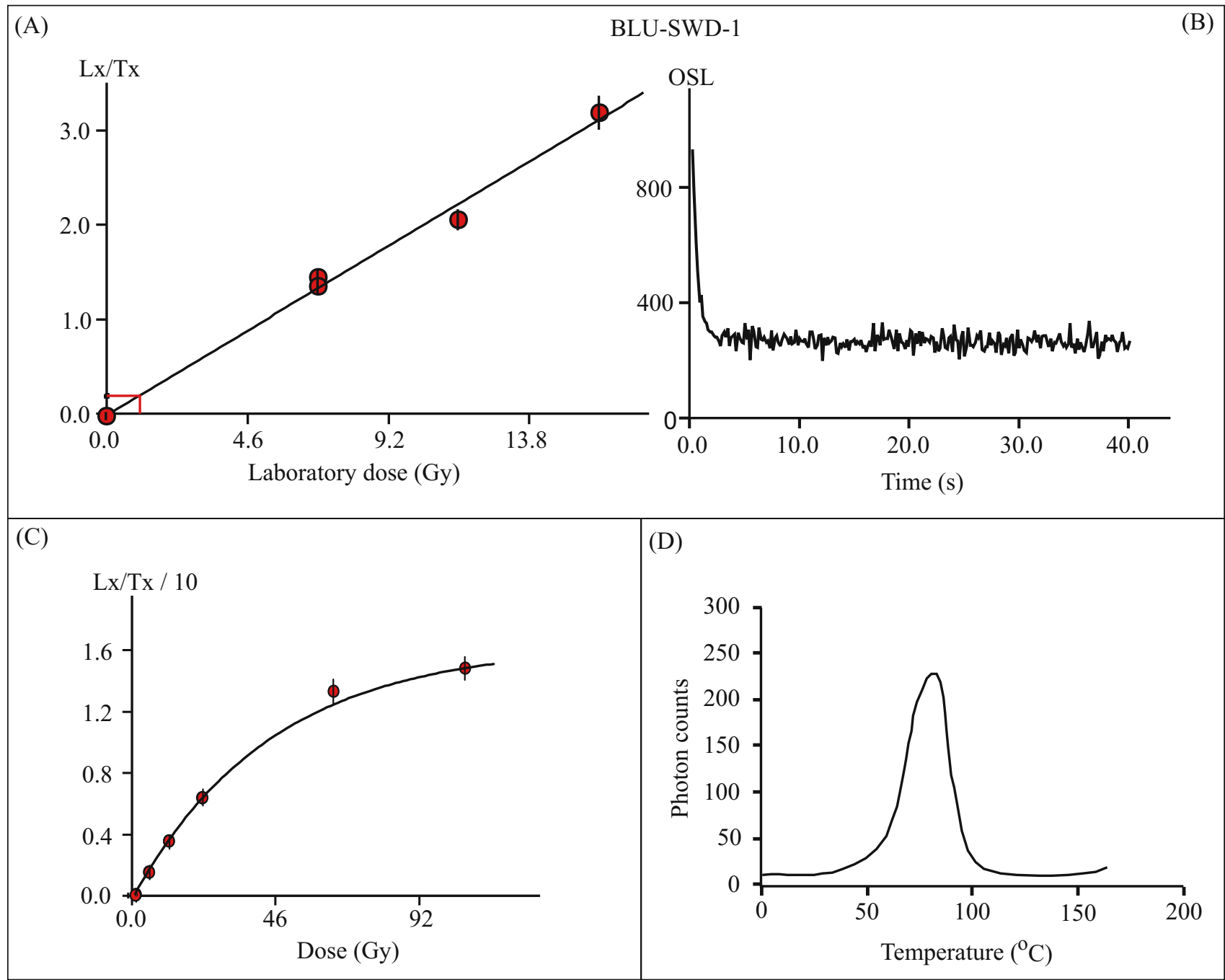

Fig. 3. (A) The laboratory generated dose growth curve for sample BLU-SWD-1. (B) shine down curve of same aliquot after a laboratory dose of $6.9 \mathrm{~Gy}$. (C) Sensitivity corrected dose growth curve to check the saturation limit (D) $110^{\circ} \mathrm{C} T \mathrm{~L}$ peak of 100 grains aliquot in response to $4.2 \mathrm{~Gy}$ laboratory dose. 
quartz was used for further analysis. Uranium $\left({ }^{238} \mathrm{U}\right)$ and thorium $\left({ }^{232} \mathrm{Th}\right)$ concentrations are measured by Inductively Coupled Plasma-Mass Spectrometer (ICP-MS) with Potassium based on XRF and double checked by ICP-MS.

\section{APPLICABILITY OF SAR}

In the standard SAR protocol, the natural luminescence is measured followed by a test dose measurement. A cycle of laboratory doses and their luminescence measurements is made with increasing the dose in each step (Murray and Wintle, 2000). The luminescence yield at each dose point is corrected for sensitivity change by measuring the OSL yield for a test dose at the end of each cycle. A plot of the sensitivity corrected regenerated OSL signal with dose enables the construction of a dose growth curve. Sensitivity corrected natural luminescence intensity is interpolated onto this growth curve to obtain the equivalent dose or palaeodose. The age of the sample is calculated by the simple age formula (Aitken, 1998):

$$
\text { Age }(\mathrm{ka})=\frac{\text { paleodose }(\mathrm{Gy})}{\text { dose accumulated }(\mathrm{Gy} / \mathrm{ka})}
$$

\section{Luminescence Intensity and dose growth curve}

In luminescence dating application, it is important to have a detectable luminescence signal from the sample. Initially single grain studies were carried out but the number of bright grains were extremely low $(<1 \%)$ and the photon counts were low. The background subtracted photon counts ranged from 400-600 per Gy over a 0.8 second integral of shine down. Thermo-luminescence (TL) record of an aliquot containing $\sim 100$ grains of quartz has been shown in Fig. 3D. The disk was dosed 4.2 Gy after removal of natural dose. It is clear that the sensitivity of quartz is extremely low as shown by $110^{\circ} \mathrm{C}$ TL peak, a representative of OSL sensitivity. Hence, the idea of single grain studies had to be dropped and single aliquot studies were chosen. Four aliquots from each sample were bleached at room temperature to remove any natural signals present and then a laboratory dose of 9.27 Gy was administered to each aliquot. Luminescence measurement was made for 40 seconds at $125^{\circ} \mathrm{C}$ after preheat of $220^{\circ} \mathrm{C}$ for 10 seconds. As shown by the shine down curve, the photon counts were well above the detection limit (Fig. 3B). All the samples have shown similar behavior, indicating a common source of quartz.

To generate a dose growth curve, two aliquots were stimulated 2 times for 40 seconds with a break of $>3$ hours to avoid the interference of any signal trapped in $110^{\circ} \mathrm{C}$ TL trap (Murray and Wintle, 2003). The aliquots were beta dosed in increasing order. After each dose, OSL was measured for 40 seconds at $125^{\circ} \mathrm{C}$ after applying preheat of $220^{\circ} \mathrm{C} / 10$ seconds. Each dose point was followed by OSL measurement of a fixed test dose measurement after a cut heat of $160^{\circ} \mathrm{C}$. Sensitivity corrected dose growth curve was constructed with a saturating exponential fitting (Fig. 3C). The growth curve saturates after $\sim 130$ Gy and thus, optical dating of quartz from this area is limited to only $\sim 35-40 \mathrm{ka}$ (considering a dose rate of $\sim 3 \mathrm{~Gy} / \mathrm{ka})$.

\section{Preheat Plateau test}

To remove unstable OSL signal arising from laboratory irradiation, preheat is an essential and important step to be carried on before making OSL measurement. Usually the equivalent dose is insensitive to the temperature range of $160-300^{\circ} \mathrm{C}$ as shown by various workers (Murray and Olley, 1999; Murray and Wintle, 2000 and Roberts et al., 1999). The aliquots were bleached twice (with a break of $>3$ hours) using blue LED for 40 seconds at room temperature to avoid any interference from luminescence signals arising from $110^{\circ} \mathrm{C}$ TL traps during first bleaching. All the aliquots were given a laboratory dose of 9.23 Gy. The doses were recovered using SAR at varying preheat temperature starting from $180^{\circ} \mathrm{C}$ up to $300^{\circ} \mathrm{C}$ with an increment of $20^{\circ} \mathrm{C}$. The cut heat for test doses
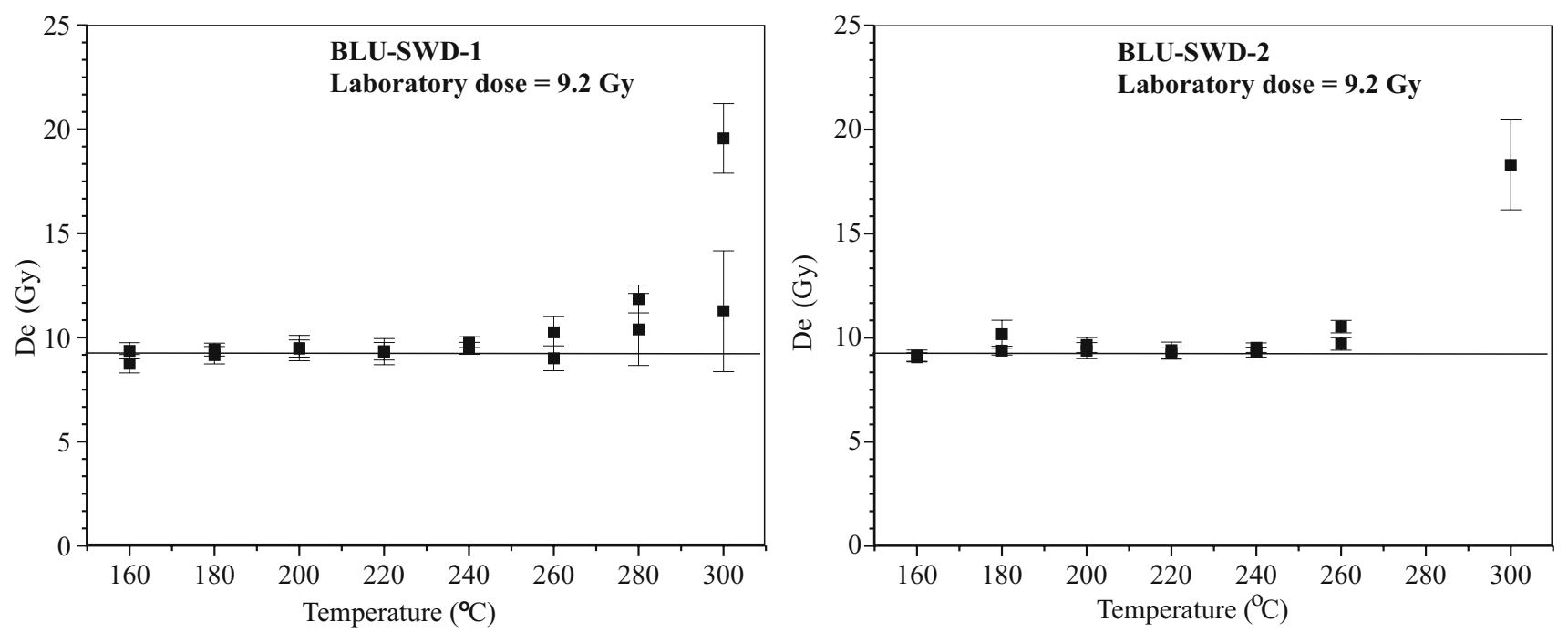

Fig. 4. Preheat plateau test of BLU-SWD-1 and BLU-SWD-2. The aliquots were dosed for 9.2 Gy and then dose were recovered using SAR at various preheat temperature. The data suggest a preheat temperature of $160-240^{\circ} \mathrm{C}$. Beyond $240^{\circ} \mathrm{C}$, the scatter increases and palaeodose is significantly off from the given dose. 
was $160^{\circ} \mathrm{C}$ for all. Three aliquots were used for each preheat temperature. The analysis was done on all of the 4 samples. The palaeodoses are stable at a temperature range of up to $240^{\circ} \mathrm{C}$ as shown by BLU-SWD-1 and 2 (Fig. 4). Beyond $240^{\circ} \mathrm{C}$, the error increases and recovered doses are offset significantly from expected doses. Based on the preheat plateau tests, preheat of $220^{\circ} \mathrm{C}$ was chosen as the optimum condition.

\section{OSL Thermal transfer}

A significant amount of transfer of charges may occur from deeper to shallower traps due to pre-heating of the natural OSL, which leads to overestimation of ages. OSL is measured while the aliquot is held at $125^{\circ} \mathrm{C}$ to minimize charge cycling through the $110^{\circ} \mathrm{C}$ TL trap and so to increase the rate of decay of the OSL signal. Rhodes and Bailey (1997) determined a significant overestimation in equivalent dose $\left(D_{e}\right)$ in zero age glacio-fluvial samples from Greenland and attributed it to the thermal transfer of the OSL signals. A number of authors have previously shown an increase in luminescence signal at higher temperature due to significant contribution due to thermal transfer (Banerjee, 2000; Wallinga et al., 2001).

The effect of thermal transfer was investigated in the samples BL5 and BL8. All aliquots were bleached twice after a break of $\sim 3$ hours using blue LED for 40 seconds at room temperature to remove any natural signal present in the sample. The equivalent dose $\left(D_{e}\right)$ was measured using SAR as suggested by Murray and Wintle (2000). The preheat temperature was set at $220^{\circ} \mathrm{C}$ for regeneration doses and $160^{\circ} \mathrm{C}$ was used to remove unstable luminescence from test dose. The linear fitting was used for dose growth curve. The results indicate that the amount of thermal transfer for sample BLU-SWD-1 (9 disks were analyzed) varies from -0.23 to 0.28 Gy (average $\sim 0.04 \pm 0.2$ Gy) (Fig. 5). For sample BLU-SWD-4 (8 disks were analysed), the thermal transfer range is within ( 0 to $0.06 \mathrm{~Gy}$ ) having an average value $0.10 \pm 0.11 \mathrm{~Gy}$. The above results show that thermal transfer has some finite value but still, it can be taken as within accepted value of the natural luminescence measured in the samples. The palaeodoses for sample BLU-SWD-2 and BLU-SWD-4 are $1.18 \pm 0.05$ and $1.15 \pm 0.06 \mathrm{~Gy}$ and the average thermal transfer is $<10 \%$ of the palaeodose.

\section{OSL Sensitivity changes}

\section{Dose recovery test}

In SAR, several cycles (6-7 cycles) of irradiation, preheat and luminescence measurements are repeated. In this process, the luminescence sensitivity changes are monitored using test doses and a recycled point equal to the first regeneration point is made to monitor if the sensitivity changes were remained within the accepted value of $10 \%$ (Murray and Wintle, 2000). Dose recovery is very important and reliable test required for determining the palaeodose using SAR. This test was applied on 21 aliquots of sample BL-5. The aliquots were bleached twice for 40 seconds (blue LED at room temperature) at an interval of $>3$ hours to remove any luminescence arising from $110^{\circ} \mathrm{C} \mathrm{TL}$ trap. A dose of $9.27 \mathrm{~Gy}$ was given to observe the variation in the precision of recovered dose. Similar test was also carried on sample BL-8.

The average $\mathrm{D}_{\mathrm{e}}$ was computed for the entire recovered $\mathrm{D}_{\mathrm{e}}$ 's. The recovered dose for sample $\mathrm{BL}-5$ is $9.29 \pm 0.36$ Gy $(n=21)$ and for sample BL-8, 9.27 $\pm 0.51 \mathrm{~Gy}$ $(n=19$; Fig. 6). The amount of recuperation was $<5 \%$ of the sensitivity corrected natural luminescence, indicating the recuperation is not a problem in the samples from the studied area.

A check on sensitivity change can be examined by comparing the test dose response $T_{x} / T_{n}\left(T_{x}=\right.$ test dose luminescence followed by regenerative doses R1, R2, R3, $\mathrm{R} 4$ and $\mathrm{R} 5, \mathrm{~T}_{\mathrm{n}}=$ test dose luminescence followed by natural OSL measurement) from various cycles in SAR. Any change in sensitivity after the natural OSL measurement should be reflected in a graph of $T_{x} / T_{n}$ vs. the number of treatment cycles (Fig. 6B). As shown in Fig. 6B, first point is cycle 1 , the ratio of $T_{n} / T_{n}=1$, and rest of the points are $T_{x} / T_{n}(x=1,2,3,4$ and 5; regeneration test dose points). The plot clearly demonstrate that sensitivity has changed in increasing order but limited to a maximum of up to $20 \%$ from the natural.

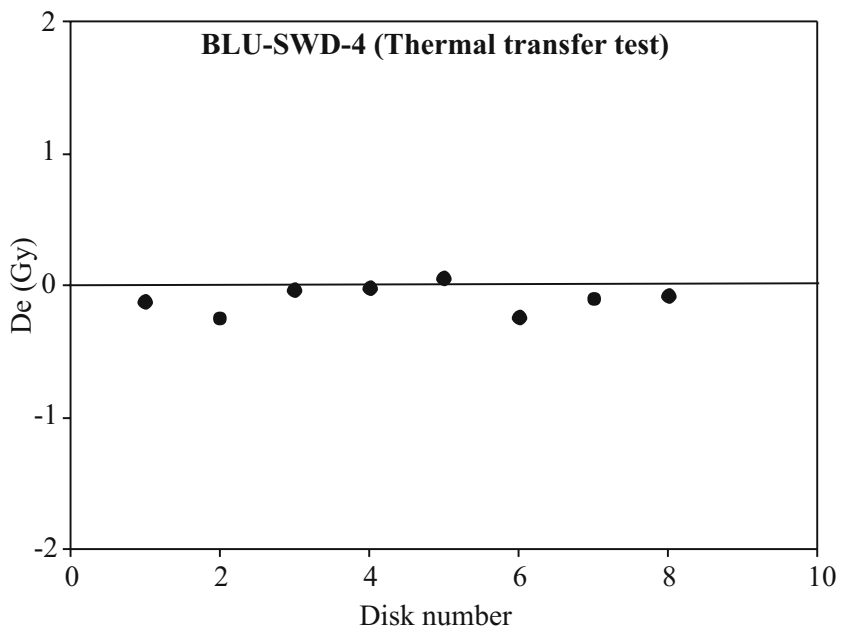

Fig. 5. Thermal transfer test on sample BLU-SWD-1 and 4 to show that transfer of charges was negligible on preheating the samples up to $220^{\circ} \mathrm{C}$. 

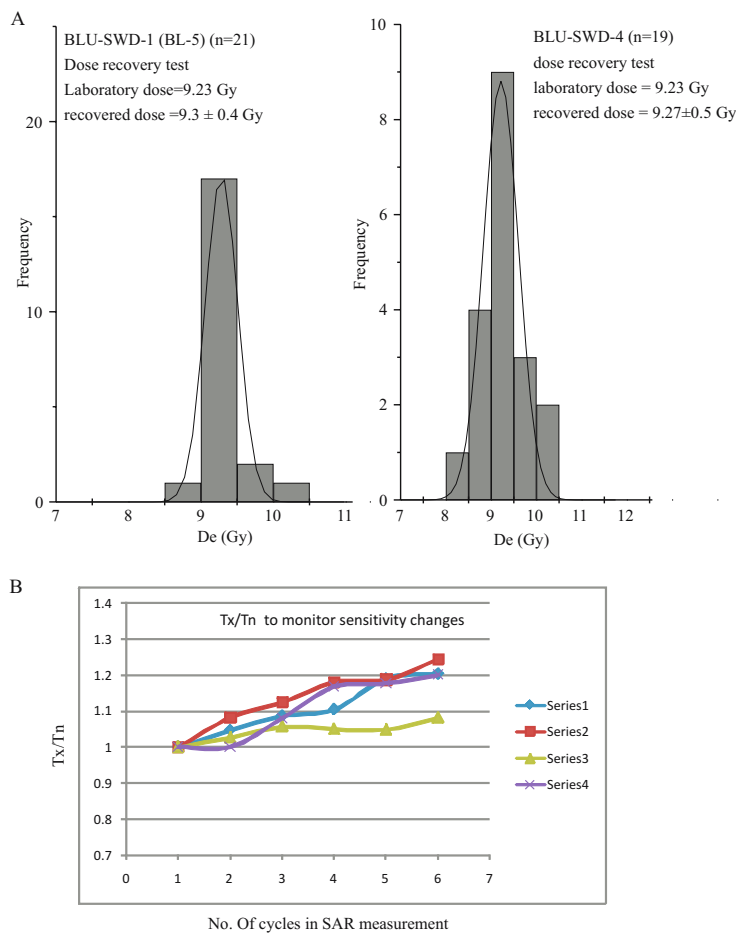

Fig. 6. (A) Dose recovery test for sample BLU-SWD-1 \& 4. The dose distribution was fitted to a Gaussian curve. (B) $T_{x} / T_{n}$ graph i.e. The ratio of test dose measurement of the consecutives regeneration cycles to the natural test dose OSL measurement. First point represent the natural OSL test dose measurement as unity.

\section{RESULTS AND DISCUSSIONS}

SAR was applied to obtain the palaeodoses after conducting various tests as discussed in section 4 . The radioactive elemental concentration and dose rate are shown in Table 1. The average of least $10 \%$ palaeodose from the modern sediment BLU-SWD-1 is derived as $0 \pm 0$ Gy as expected (Table 2). The dose distribution is displayed in the histogram supplemented by radial plot (Gailbraith, 1990) in Fig. 7 for better visualization. Six out of 19 palaeodoses gave negative values, although close to zero (cannot go in radial plots due to 0 values), indicating that SAR on small aliquot is enough to resolve the bleached portion in partially bleached sediment (Fig. 7, Table 2). The average palaeodose (keeping all negative values as 0 and excluding three highest palaeodoses out of shaded region in the radial plot, Fig. 7) was $0.3 \pm 0.4$ Gy giving an age of 220 years (Table 2). This show that average ages will be off (overestimated) by
Table 1. $U, T h, K$ and dose rate in the studied samples.

\begin{tabular}{|c|c|c|c|c|}
\hline \multirow[t]{2}{*}{ Sample } & \multicolumn{3}{|c|}{$\begin{array}{l}\text { Radioactive element } \\
\text { concentration }\end{array}$} & \multirow{2}{*}{$\begin{array}{l}\text { Dose rate } \\
\text { (Gy/ka) }\end{array}$} \\
\hline & $\mathrm{U}(\mathrm{ppm})$ & Th (ppm) & $\mathrm{K}(\%)$ & \\
\hline BLU-SWD-1 & $0.46 \pm 0.01$ & $3.95 \pm 0.04$ & 1.26 & $1.38 \pm 0.1$ \\
\hline BLU-SWD-2 & $0.47 \pm 0.01$ & $7.20 \pm 0.05$ & 0.72 & $1.22 \pm 0.1$ \\
\hline BLU-SWD-3 & $0.52 \pm 0.01$ & $9.31 \pm 0.64$ & 1.01 & $1.57 \pm 0.1$ \\
\hline BLU-SWD-4 & $0.73 \pm 0.01$ & $6.12 \pm 0.59$ & 1.06 & $1.44 \pm 0.1$ \\
\hline
\end{tabular}

220 years. Similarly, the other sample (BLU-SWD-3) close to modern age, have yielded an average palaeodose of $0.43 \pm 0.04$ Gy giving an age of $270 \pm 30$ years, equivalent to an offset of $\sim 230$ years from the $40 \pm 40$ years, based on the least $10 \%$ palaeodose. The offset is similar as compared to the modern sediment BLU-SWD-1, suggesting that amount of bleaching also remains the same in this sample and the true age should be based on the least values. As suggested by Bailey and Arnold (2006), the minimum age model (MAM) will not work for modern age samples or if we get a negative $\mathrm{D}_{\mathrm{e}}$ value. In this case, minimum age model palaeodose and ages were not considered using MAM for BLU-SWD-1 and 3.

Average and least $10 \%$ palaeodoses of sample BLUSWD-2 are $1.18 \pm 0.05$ and $0.83 \pm 0.04 \mathrm{~Gy}$, giving an age of $970 \pm 90$ and $680 \pm 60$ years respectively. The MAM ages for this sample is $900 \pm 260$ years, overestimating the least $10 \%$ age, however due to large error, it might be ignored in the present case. The palaeodoses distribution is well clustered around the mean value and possibly shows a Gaussian distribution (Fig. 7). The offset of least and average age is $\sim 190$ years, similar to the modern samples discussed above. In that case, age based on least palaeodoses should be close to true age of the sample. Similarly for the sample BLU-SWD-4, the average and least age are $800 \pm 70$ and $520 \pm 50$ years, showing an offset of 280 years. The MAM age for this sample is $660 \pm 280$ years and represent an average of least $10 \%$ (520 years) and mean ( 800 years) ages. Due to large error, we suggest that the lowest $10 \%$ ages should be preferred over MAM ages. An offset of 0.3-0.4 Gy has been observed in all the samples between the least and average residual palaeodose. From above results, it seems that in a slack water deposit from the study area, the amount of partial bleaching is in the range of 0.3-0.4 Gy equivalent to age range of 200-300 years for a dose rate of $\sim 1.5 \mathrm{~Gy} / \mathrm{ka}$. Studies on modern samples shows that average ages may be overestimated by 200-300 years and

Table 2. De's and corresponding ages based on Min 10\%, Minimum age model (MAM) and Mean of all $D_{e}$ 's.

\begin{tabular}{|c|c|c|c|c|c|c|c|}
\hline \multirow{2}{*}{ Sample } & \multicolumn{3}{|c|}{$D_{e}(G y)$} & \multicolumn{3}{|c|}{ Age (Years) } & \multirow{2}{*}{ No. of disks } \\
\hline & $\operatorname{Min} 10 \%$ & MAM & Mean & Min 10\% & MAM & Mean & \\
\hline BLU-SWD-1 & $0 \pm 0$ & - & $0.3 \pm 0.4$ & $0 \pm 0$ & - & $220 \pm 290$ & 19 \\
\hline BLU-SWD-2 & $0.83 \pm 0.04$ & $1.1 \pm 0.3$ & $1.18 \pm 0.05$ & $680 \pm 60$ & $900 \pm 260$ & $970 \pm 90$ & 24 \\
\hline BLU-SWD-3 & $0.06 \pm 0.07$ & - & $0.43 \pm 0.04$ & $40 \pm 40$ & - & $270 \pm 30$ & 28 \\
\hline BLU-SWD-4 & $0.75 \pm 0.04$ & $0.92 \pm 0.38$ & $1.15 \pm 0.06$ & $520 \pm 50$ & $660 \pm 280$ & $800 \pm 70$ & 26 \\
\hline
\end{tabular}



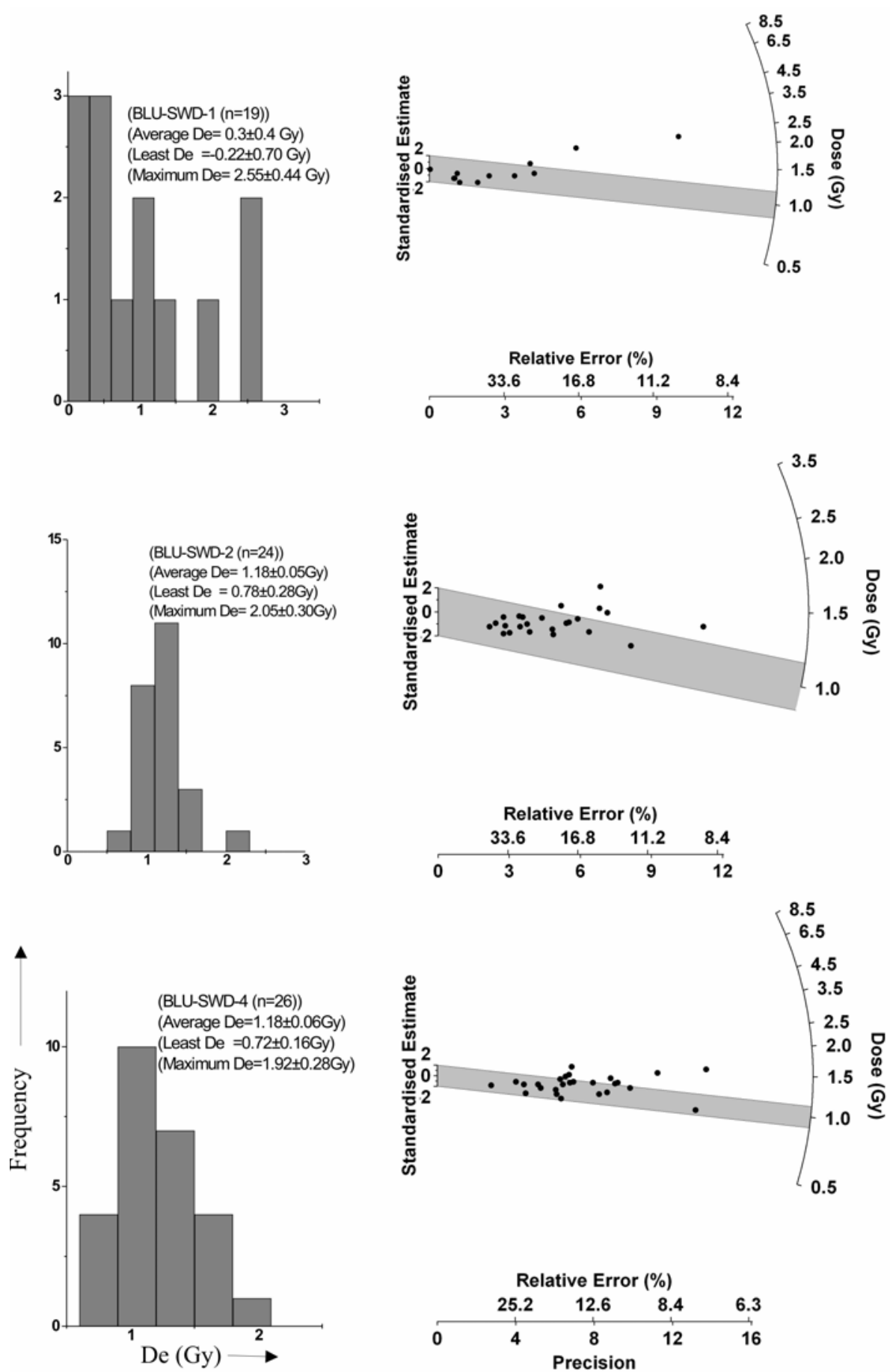

Fig. 7. Histograms of palaeodose distributions of Samples BLU-SWD-1,2 and 4 supported by respective radial plots. Least $5 \%$ was the true palaeodose in case of modern deposit BLU-SWD-1.

thus true ages should be calculated from least palaeodoses.

\section{CONCLUSIONS}

Based on above results and the discussions, following conclusions can be drawn:

1) Even though of low sensitivity and very low percentage of bright grains various tests shows that SAR can be applied successfully to resolve the unbleached part from the partial bleached samples shown by residual luminescence on modern samples.

2) A typical residual luminescence of 0.3-0.4 Gy equivalent to $\sim 200-300$ years of age is obtained for such deposit and thus should not be an obstacle for optical dating for younger deposit of the order of a few ka in age.

3) The lowest $10 \%$ of $D_{e}$ 's are suggested to be used to calculate the palaeodose for young slack-water deposit of a few hundred years old - at least in this region and similar environments. 


\section{ACKNOWLEDGEMENTS}

This study is financially supported by National Science Council and Central Geological Survey, Taiwan under grant numbers NSC94-2119-M-002-002 and NSC952119-M-002-041. The authors acknowledges Dr. C.Y. Lee for XRF analysis.

\section{REFERENCES}

Aitken MJ, 1998. An introduction to optical dating. Oxford, Oxford University Press: 267pp.

Baker VR, Kochel RC and Patton PC, eds., 1988. Flood Geomorphology: New York, John Wiley: 503 pp.

Bailey RM and Arnold LJ, 2006. Statistical modeling of single grain quartz $\mathrm{D}_{\mathrm{e}}$ distributions and an assessment of procedures for estimating burial dose. Quaternary Science Reviews 25: 2475-2502, DOI 10.1016/j.quascirev.2005.09.012.

Banerjee D, 2000. Thermal transfer and recuperation in quartz OSL and their consequences regarding optical dating procedure. In: Murthy KVR et al., eds., Luminescence and its applications. Luminescence Society of India C 1/2000: 86-93.

Berger GW and Luternauer JJ, 1987. Preliminary fieldwork for Thermoluminescence dating: Studies at the Fraser river delta, British Columbia. Geological Survey of Canada Paper 87: 901-904.

Berger GW, 1990. Effectiveness of natural zeroing of the thermoluminescence in sediments. Journal of Geophysical Research 95: 12375-12397.

Ditlefsen C, 1992. Bleaching of K-feldspar in turbid water suspensions: A comparison of photo and thermoluminescence signals. Quaternary Science Reviews 11: 33-38, DOI 10.1016/02773791(92)90039-B.

Fuchs $\mathrm{M}$ and Wagner GA, 2003. Recognition of insufficient bleaching by small aliquots of quartz for reconstructing soil erosion in Greece. Quaternary Science Reviews 22: 1161-1167, DOI 10.1016/S0277-3791(03)00039-8.

Fuchs M, Straub J and Zoller L, 2005. Residual luminescence signal of recent river flood sediments: A comparison between quartz and feldspar of fine- and coarse-grain sediments. Ancient TL 23: 25-30.

Galbraith RF, 1990. The radial plot: graphical assessment of spread in ages. Nuclear Tracks and Radiation Measurement 17: 207-214, DOI 10.1016/1359-0189(90)90036-W.

Jain M, Murray AS and Botter-Jensen L, 2004. Optically Stimulated Luminescence Dating: How significant is incomplete light exposure in fluvial environments? Quaternaire 15(1-2): 143-157.

Jaiswal MK, 2006. Optically Stimulated Luminescence Dating of fluvial sediments: Applications and Implications to palaeoseismology and Palaeocliamtology. Thesis submitted to M.S. University of Baroda. Vadodara, India: pp 139.

Kale VS, Mishra S and Baker VR, 2003. Sedimentary record of palaeofloods in the bedrock gorges of the Tapi and Narmada rivers, central India. Current Science 84: 1072-1079.

Kale VS, Singhvi AK, Mishra PK and Banerjee D, 2000. Sedimentary record and luminescence chronology of Late Holocene palaeofloods in the Luni river, Thar desert, northwest India. Catena 40: 337-358, DOI 10.1016/S0341-8162(00)00091-6.

Murray AS and Olley JM, 1999. Determining sedimentation rates using luminescence dates. In: Bruns P and Hass HC, eds., Determinations of sediment accumulation rates. Georesearch forum, Trans Tech publications, Switzerland: 121-144.

Murray AS and Wintle AG, 2000. Luminescence dating of quartz using an improved single aliquot regenerative-dose protocol. Radiation Measurements 32: 57-73, DOI 10.1016/S1350-4487(99)00253-X.

Murray AS and Wintle AG, 2003. The single aliquot regenerative dose protocol: potential for improvements in reliability. Radiation Measurements 37: 377-381, DOI 10.1016/S1350-4487(03)000532.

Olley JM, Caitcheon G, and Murray A, 1998. The distribution of apparent dose as determined by optically stimulated luminescence in small aliquots of fluvial Quartz: implications for dating young sediments. Quaternary Science Reviews 17: 1033-1040, DOI 10.1016/S0277-3791(97)00090-5.

Rhodes EJ and Bailey RM, 1997. Thermal transfer effects observed in the luminescence of quartz from recent glaciofluvial sediments. Quaternary Sciences Reviews 16: 291-298, DOI 10.1016/S02773791(96)00100-X.

Roberts RG, Galbraith R, Olley JM, Yoshida H and Laslett G, 1999. Optical dating of single and multiple grains of quartz from Jinmium Rock shelter, northern Australia, Part II: Results and Implications. Archaeometry 41: 365-395, DOI 10.1111/j.14754754.1999.tb00988.x.

Sharma A and Rajamani V, 2001. Weathering of charnockites and sediment production in the catchment area of the Cauvery River, southern India. Sedimentary Geology 143: 169-184, DOI 10.1016/S0037-0738(01)00102-6.

Spooner NA, 1993. The validity of optical dating based on feldspar. Unpublished D. Phil thesis, Oxford University.

Stokes S, Bray HE and Blum MD, 2001. Optical resetting in large drainage basins: tests of zeroing assumptions using single aliquot procedures. Quaternary Sciences Reviews (Quaternary Geochronology) 20: 879-885, DOI 10.1016/S0277-3791(00)00045-7.

Wallinga J, Murray AS, Duller GAT and Törnqvist TE, 2001. Testing optically stimulated luminescence of sand-sized quartz and feldspar from fluvial deposit. Earth and Planetary Sciences Letter 193: 617- 630, DOI 10.1016/S0012-821X(01)00526-X. 